\title{
LOS SISTEMAS DE INFORMACIÓN GEOGRÁFICA EN TURISMO
}

Miguel R. Luaces

Oscar Pedreira

Ángeles S. Places

Diego Seco

Universidade da Coruña

\begin{abstract}
Resumen:
Internet se ha convertido en uno de los lugares más populares para publicar y buscar casi cualquier tipo de información. En particular, la información turística ha ganado mucha atención en la red durante los últimos años, no sólo información sobre viajes, recursos, lugares, museos o monumentos, sino también sobre turismo cultural.

En este artículo presentamos las posibilidades que ofrecen los Sistemas de Información Geográfica (SIG) en la publicación y acceso a información turística, a través de interfaces con capacidades de generación de mapas interactivos con información asociada a cada elemento de interés presentado en los mapas.

Además, describimos como caso de estudio el Viaje Virtual de la Biblioteca Virtual Gallega (http://bvg.udc.es), un sistema accesible a través de la Web que, utilizando tecnologías SIG, permite acceder a cualquier información turística o cultural de Galicia de manera sencilla.
\end{abstract}

Palabras clave. Internet, turismo, cultura, interfaces Web, SIG.

Resumo: Os sistemas de información xeográfica no turismo

A internet converteuse nun dos lugares máis populares para publicar e buscar case calquera tipo de información. En particular, a información turística gañou moita atención na rede durante os últimos anos, e non só a información sobre viaxes, recursos, lugares, museos ou monumentos, senón tamén sobre turismo cultural.

Neste artigo presentamos as posibilidades que ofrecen os sistemas de información xeográfica (SIX) para a publicación de información turística e o acceso a ela, a través de interfaces coa capacidade de xerar mapas interactivos que presenten información asociada a cada elemento de interese que apareza neles. Ademais, describimos como caso de estudo a viaxe virtual que se nos propón na Biblioteca Virtual Galega (http://bvg.udc.es), un sistema accesible a través da web que, por medio de tecnoloxías SIX, permite acceder a calquera información turística ou cultural de Galicia de xeito sinxelo.

Palabras clave: Internet, turismo, cultura, interfaces Web, SIX.

Abstract: Geographic Information Systems in Tourism

The Internet has become one of the most popular places to publish and search for almost any type of information. In particular, tourist information has received much attention in the 
Internet over the past few years, not only information about travel, resources, places, museums or monuments, but also about cultural tourism.

In this article we discuss the potential offered by Geographic Information Systems (GIS) in the publication of and access to tourist information, through interfaces capable of generating interactive maps with information associated with each element of interest shown in the maps.

In addition, as a case study, we describe the Virtual Trip of the Galician Virtual Library (http://bvg.udc.es), an Internet-accessible system which makes it possible, using GIS technologies, to easily access any tourist or cultural information about Galicia.

Key words: Internet, tourism, culture, Web interfaces, GIS.

\section{INTRODUCCIÓN}

La importante expansión de Internet ha creado un nuevo foro de intercambio de información que permite hacerla accesible de una forma más rápida y barata debido a que no tiene que pasar a través de todo el proceso que es necesario para publicar un libro, una revista o un folleto. De esta manera, Internet ha llegado a ser un medio adecuado para difundir cualquier tipo de información de tal forma que el turismo, como casi cualquier otro campo, puede obtener ventajas de él.

El diseño de interfaces Web adecuadas para la búsqueda y visualización de información por usuarios no experimentados ha atraído mucha atención en los últimos años. Este elemento es especialmente importante cuando se trata de información turística debido a los diferentes niveles de habilidad de los usuarios y a que estos sistemas de información combinan datos de diferentes fuentes (mapas, imágenes, sonido, vídeo, texto, etc.). Muchas de las interfaces que nos podemos encontrar hoy en día en la Web emplean texto junto con imágenes estáticas, o pueden incluso presentar una combinación de texto, imágenes, sonido y vídeo con mapas. Aunque esta aproximación puede ser satisfactoria, suele ser "estática", en el sentido de que los usuarios sólo pueden realizar operaciones como zoom en un mapa o ver un vídeo, pero no pueden interactuar realmente con la página Web.

Una interfaz ideal para una página Web con información turística debe ofrecer la información anterior, pero también la posibilidad de interactuar con ella. Por ejemplo, si un usuario está interesado en lugares arqueológicos, la interfaz puede ocultar en el mapa el resto de información (como museos, hoteles, etc.) y así tener una vista más clara de lo que está buscando. Otra posibilidad, especialmente útil para el turismo cultural, es tener algunas rutas predefinidas tales como itinerarios turísticos o de peregrinación de especial interés para el país o la región. Además, este portal Web podría incluir capacidades de comercio electrónico, incluyendo reservas en hoteles o tickets de viaje.

En el desarrollo de la interfaz del Viaje Virtual a través de Galicia, incluido en la Biblioteca Virtual Gallega (disponible en http://bvg.udc.es), hemos seguido como directriz principal el uso de metáforas cognitivas, con el objetivo de que dicha interfaz resulte intuitiva y fácil de utilizar a los usuarios. Emplear una metáfora cognitiva 
implica el uso de "algo" del mundo real bien conocido por el usuario; si el usuario conoce a qué se parece una interfaz y cómo funciona el elemento original, se sentirá más cómodo utilizándola. Dado que estamos ofreciendo, además de otros datos, información geográfica (dónde se ubica una playa o un museo, por ejemplo), esto nos permite usar un mapa de Galicia como la metáfora cognitiva principal de nuestro sistema. Esto también implica el uso de un Sistema de Información Geográfica (SIG) para gestionar los datos y referencias geográficas. Nuestra experiencia en el desarrollo de aplicaciones con sistemas SIG (Brisaboa et al., 2006; Brisaboa et al., 2007; González et al., 2007) nos ayudó a integrar de manera sencilla la base de datos y el subsistema SIG.

Con este objetivo en mente, hemos desarrollado una interfaz Web, incluida en la Biblioteca Virtual Gallega, que ofrece un servicio llamado "Viaje Virtual a través de Galicia". Este nuevo servicio ofrece información sobre la cultura gallega incluyendo monumentos, museos, nuestros recursos naturales y turísticos (playas, casas rurales, balnearios, etc.) y permitirá una especie de "turismo cultural" a través de Galicia.

El Viaje Virtual muestra un interés especial en el turismo cultural ya que Galicia tiene mucho que ofrecer en este sentido. Podemos distinguir varios tipos de turistas, entre los que podemos destacar los siguientes:

- Gallegos que quieran aprender más acerca de nuestra región y su historia.

- La diáspora gallega: incluyendo la primera, segunda y tercera generación. Es especialmente importante debido a que casi el 25\% de los habitantes de Galicia emigraron a Europa y a las Américas a finales del siglo XIX y primera mitad del XX.

- Turistas procedentes de la Península Ibérica (España y Portugal), con conocimiento parcial sobre Galicia pero no sobre nuestra cultura y patrimonio.

- Turistas que visitarán Galicia, o incluso España, por primera vez y no tengan conocimiento de nuestra cultura.

Con estos posibles turistas en mente, hemos puesto un gran empeño en el diseño de una interfaz Web para el sistema que utiliza un SIG (Worboys, 2000; Longley et al., 2001; Taboada González, 2005) y una base de datos multimedia. Esta base de datos almacena la información de lugares con cualquier tipo de interés turístico o que tengan recursos turísticos o naturales. Todos estos lugares se muestran en un mapa interactivo junto con información multimedia asociada con ellos. Debemos hacer constar, sin embargo, que nuestra interfaz se visualiza completamente en gallego y, por tanto, sólo serán capaces de usarla personas que conozcan este idioma (probablemente los dos primeros tipos de turistas posibles mostrados arriba). El sistema ofrecerá traducciones de la interfaz a varios idiomas (español, inglés, etc.) en un futuro próximo.

El resto de este artículo está organizado como sigue. En primer lugar, en las secciones 2 y 3 , ofrecemos una visión general de los sistemas SIG y del diseño de interfaces de usuario. La Sección 4 describe la Biblioteca Virtual Gallega, el marco donde se localiza el Viaje Virtual a través de Galicia. Luego, en la Sección 5, se explican los detalles técnicos acerca del sistema y la descripción de cómo funciona su interfaz se detalla en la Sección 6. La última sección ofrece nuestras conclusiones. 


\section{SISTEMAS DE INFORMACIÓN GEOGRÁFICA}

La mejora exponencial del rendimiento de los computadores ha hecho posible la aparición de nuevas herramientas para manipular las características geográficas (espaciales) de los objetos permitiendo su representación gráfica sobre un mapa. Los Sistemas de Información Geográfica (SIG) están un paso por delante de los sistemas de información tradicionales, ofreciendo un entorno adecuado para la captura, almacenamiento y gestión tanto de la información geográfica como de la no geográfica.

La inclusión de la información espacial en el estándar de acceso a bases de datos SQL:1999 (Zetie, 1995) o los desarrollos realizados por el Open Geospatial Consortium (http://www.opengis.org) son un buen indicador de la importancia de la gestión de la información espacial y, por tanto, geográfica. Por información geográfica entendemos información sobre la localización espacial de los objetos. Esta información puede ser tan sencilla como la posición en el mapa de todos los museos de un país o tan compleja como la división de un país en zonas respecto a su clima, áreas administrativas, etc.

En esta sección revisaremos brevemente algunas de las características de un Sistema de Información Geográfica. Es conocido que un SIG tiene un componente gráfico muy importante dado que la manera más sencilla de evaluar la información geográfica es visualmente. Sin embargo, un SIG proporciona mucho más que un simple procesado de gráficos. Aunque en un SIG la información geográfica es fundamental, puede haber información igualmente importante accesible a través de él. Esta información abarca desde los habituales datos estructurados almacenados en una base de datos hasta información multimedia, y está normalmente vinculada a un "lugar" espacial específico. Por lo tanto, deberemos tratar con los siguientes tipos de información:

- Datos tradicionales o estructurados: Éste es el tipo de información empleado en bases de datos tales como valores numéricos, cadenas de caracteres o fechas. Por ejemplo, el nombre de un río o la población de una ciudad.

- Datos multimedia: Esto incluye imágenes, videos o sonidos. Por ejemplo, una foto de un museo o un himno nacional.

- Datos espaciales: Ésta es la información gestionada por un SIG y la definiremos a continuación.

La información espacial se puede almacenar empleando una gran variedad de formatos, siendo los más comunes el formato vectorial y el ráster. Los formatos vectoriales permiten una mayor precisión y algoritmos más complejos, y son adecuados para dominios discretos (representaciones de objetos espaciales individuales de forma separada). Los formatos ráster representan un espacio (continuo) empleando un conjunto finito de celdas (píxeles) y es adecuado para tratar con espacios continuos, representando posiciones geográficas de forma aproximada. Empleando cualquiera de estos formatos, las entidades que se deban referenciar geográficamente tendrán asociado un atributo geometría y este atributo puede pertenecer a cualquiera de los tres tipos siguientes:

- Un punto, el cual representa un simple punto en un plano Euclídeo. Se emplea para almacenar la posición de un objeto. 
- Una línea, la cual es una colección de segmentos. Se emplea frecuentemente para describir rutas o carreteras.

- Un área, la cual es una colección de polígonos (que pueden contener, o no, uno o más agujeros). Se emplea para representar una superficie.

Además, los elementos geográficos se emplean habitualmente dispuestos en capas. Una capa agrupa elementos que pertenecen a la misma categoría. Por ejemplo, podemos emplear una capa para gestionar los ríos en un mapa y una capa diferente para tratar con la red de carreteras en el mismo mapa. Estas capas pueden ser gestionadas como un todo de tal forma que, por ejemplo, se pueden visualizar todas las carreteras al mismo tiempo o se puede realizar una consulta que afecte a todos los ríos.

La Figura 1 muestra un mapa de una región donde se están visualizando cuatro capas (museos, espacios naturales, ríos y yacimientos) y las demás están ocultas. El empleo de capas es una de las técnicas que proponemos para proporcionar al usuario la capacidad de interactuar con el mapa.

Figura 1. Un mapa con varias capas activas



El resto de la información (no espacial) empleada en un SIG, cuya naturaleza y cantidad dependen del uso del SIG, es habitualmente gestionada por un Sistema Gestor 
de Bases de Datos (SGBD) pero siempre está vinculada con un elemento geográfico. La Figura 2 muestra una ventana con la información estructurada (como el nombre del lugar) y multimedia (su foto) obtenida desde una localización geográfica. Esta ventana aparece cuando hacemos clic sobre el objeto (en este caso, un monumento) que se encuentra en el mapa.

Figura 2. Accediendo a la información enlazada con una localización

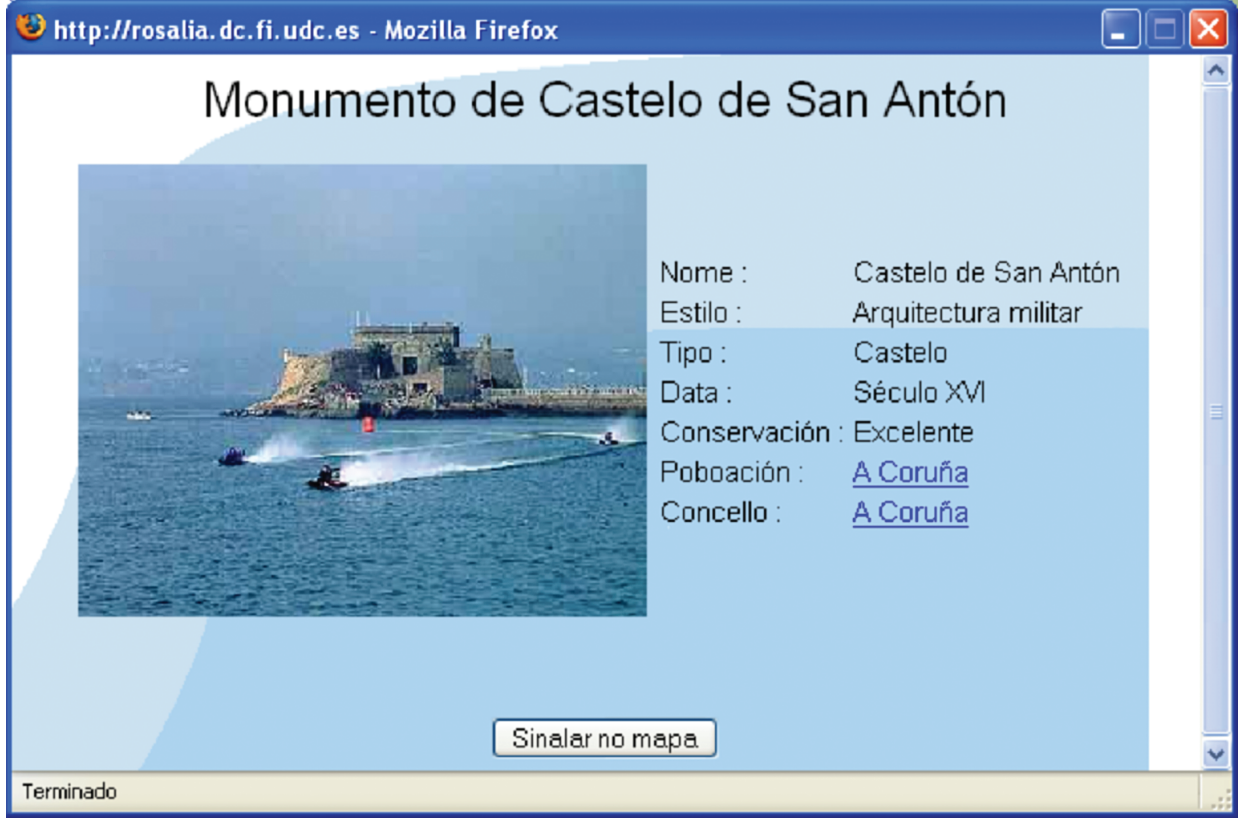

\section{DISEÑANDO LAS INTERFACES DE USUARIO}

El diseño e implementación de interfaces amigables y fáciles de utilizar ha obtenido mucha atención en los últimos años, desde la idea original y obsoleta de que la interfaz es una "capa de azúcar" para una aplicación hasta considerar que es tan importante como cualquier otro aspecto de cualquier aplicación software. Este aspecto es fundamental cuando se construye una aplicación Web donde nos podemos encontrar usuarios con niveles de habilidad muy diferentes. Por lo tanto, es crucial que cualquier usuario con habilidades mínimas para manejar un navegador Web sea capaz de emplear el sistema y encontrar toda la información de interés para él.

Para lograr este objetivo, hemos decidido emplear diferentes técnicas bien conocidas en el campo de investigación de Interacción Humano-Computador (Preece, 1994; Schneiderman, 1997; Zetie, 1995). La más importante de ellas es el uso de metáforas cognitivas (también conocidas como analogías). 
La técnica de la metáfora cognitiva está basada en un principio simple pero efectivo: propone el uso de algo conocido por el usuario traducido a un nuevo dominio, en nuestro caso una interfaz gráfica. Un ejemplo común de una analogía ampliamente empleada es la calculadora que ofrece casi cualquier sistema operativo, como Microsoft Windows. Está claro que la mayoría de los usuarios conocerán a qué se parece una calculadora y cómo funciona. Por tanto, el empleo de un programa que presente un aspecto similar y tenga las mismas funcionalidades que una calculadora real no supondrá ningún problema para un usuario común. Como veremos en la Sección 6, hemos decidido emplear un mapa de Galicia como metáfora cognitiva para el Viaje Virtual a través de Galicia.

\subsection{CUESTIONES ESPECÍFICAS ACERCA DEL VIAJE VIRTUAL}

El Viaje Virtual está pensado para ser usado como guía turística sobre Galicia. Sin embargo, no es nuestra intención ofrecer los "clásicos" servicios turísticos para turismo masivo, por lo que no ofrecemos, por el momento, información como la localización de hoteles o su disponibilidad. Debido a su historia y topografía, Galicia se conoce mejor visitando pequeños pueblos o lugares que, aparte de su belleza, tienen un considerable interés histórico. Los habitantes de estos pequeños lugares están orgullosos de su comunidad local, de su patrimonio, de su mitología local y también de dar la bienvenida a sus visitantes.

Por tanto, nuestro objetivo es proporcionar a los potenciales turistas la información necesaria para construir sus propias rutas, de tal forma que puedan hacer de manera sencilla un plan de turismo cultural agradable. Estos potenciales turistas, que viajan por diversión, cultura y aventura, quieren conocer lugares y gente, e involucrarse en las actividades locales. Este turismo tiene varios tipos de sinergias y beneficios indirectos, ayudando a llenar vacíos culturales, y puede ser promovido ofreciendo los servicios adecuados en una página Web.

Teniendo en cuenta estos aspectos, el Viaje Virtual pretende ser una herramienta no sólo de búsqueda para un lugar específico, sino también que sea capaz de organizar diferentes tipos de viajes. Por ejemplo, los usuarios serán capaces de planear un viaje cultural, visitando museos y monumentos, u otro más "aventurero" a través de ríos, paisajes y espacios naturales, descansando en balnearios o casas rurales que se encuentren en la ruta.

Como analizamos en la introducción, existen varios tipos de turistas potenciales y nuestro objetivo es satisfacer las necesidades de todos ellos. Por tanto, por ejemplo, ofrecemos rutas literarias, útiles para personas con algún conocimiento sobre nuestra cultura. Sería muy interesante para un niño que estudie a Ánxel Fole (prominente escritor gallego del siglo XX) conocer la ruta por la que viajó para entender mejor sus trabajos. Para una audiencia más amplia, están disponibles lugares de interés más específicos como playas, balnearios o museos, y la red de carreteras para alcanzarlos.

Si los usuarios planeasen estos viajes de manera clásica emplearían un mapa para localizar los lugares de interés. Por tanto, nosotros deberíamos emplear un mapa como la principal metáfora cognitiva para nuestra interfaz. Tenemos la ventaja de que prácticamente todo el mundo puede usar un mapa porque lo entiende. Esto es, si se encuentra 
una línea azul se identifica inmediatamente como un río o un triángulo negro se interpreta como una cima o una montaña. Cualquier usuario puede navegar a través del mapa con sólo mover el puntero del ratón sobre él, lo cual es bastante cercano a lo que hacemos con un mapa normal. ¿Quién no ha movido su dedo a lo largo de una carretera en un mapa para encontrar el siguiente cruce hacia alguna población? Estos aspectos se explican en detalle en la Sección 6.

\section{EL PROYECTO DE LA BIBLIOTECA VIRTUAL GALLEGA}

El "Viaje Virtual a través de Galicia" está disponible en el sitio Web de la Biblioteca Virtual Gallega (http://bvg.udc.es). La Biblioteca Virtual Gallega es un proyecto creado con dos objetivos principales: difundir la cultura y literatura de Galicia, y ofrecer un punto de acceso centralizado a cualquier tipo de información sobre Galicia. Todo esto con el fin de superar la carencia de sistematización presente en los contenidos actuales de las páginas Web de Galicia, las cuales son descentralizadas y dispersas, sin un enlace en común. Con estos objetivos en mente, tratamos de ofrecer un punto de acceso centralizado a cualquier tipo de información sobre Galicia, su cultura y su literatura, pero también otros aspectos importantes como información turística, periódicos, universidades, etc.

\subsection{LA PÁGINA WEB DE LA BIBLIOTECA VIRTUAL GALLEGA}

La inauguración de la Biblioteca Virtual Gallega (BVG) tuvo lugar en febrero de 2002 y está disponible en http://bvg.udc.es. La Figura 3 muestra su entrada principal. La descripción de esta biblioteca virtual está fuera del alcance de este artículo, pero queremos destacar sus partes principales para poder centrar el Viaje Virtual a través de Galicia. La página principal contiene varias partes diferenciadas:

- La Biblioteca Virtual, en la parte central. Proporciona acceso a los trabajos literarios disponibles en la biblioteca en varios formatos (páginas HTML, páginas digitalizadas de libros antiguos e incluso ficheros de audio y vídeos).

Es importante fijarse que en toda la Biblioteca Virtual se hace uso de metáforas cognitivas. Por ejemplo, la TV y conjunto de vídeos conducen a los vídeos disponibles, y los estantes y cajones son una manera visual e intuitiva de clasificar las escrituras disponibles.

El catálogo de la Biblioteca Virtual Gallega incluye unos 347 autores y varios miles de trabajos, de los cuales algunos están disponibles para lectura, como textos, páginas HTML o imágenes. Hay también archivos de audio (autores leyendo sus trabajos o escritores destacados leyendo libros clásicos) y archivos de vídeo de la misma naturaleza. Estos trabajos incluyen autores clásicos pero también noveles, los cuales pueden enviar sus contribuciones mediante un servicio especial ofrecido por la Biblioteca Virtual, la sección de "Nuevos autores" o "Sección de Novos". Los trabajos presentados por los nuevos autores están disponibles para su lectura y el público puede realizar comentarios acerca de esos trabajos, de 
tal manera que los nuevos autores pueden obtener opiniones y una retroalimentación sobre sus trabajos. También hay una "competición" donde los nuevos autores obtienen calificaciones para sus trabajos y el ganador se convertirá en un autor "normal" en nuestra biblioteca.

Figura 3. La Biblioteca Virtual Gallega

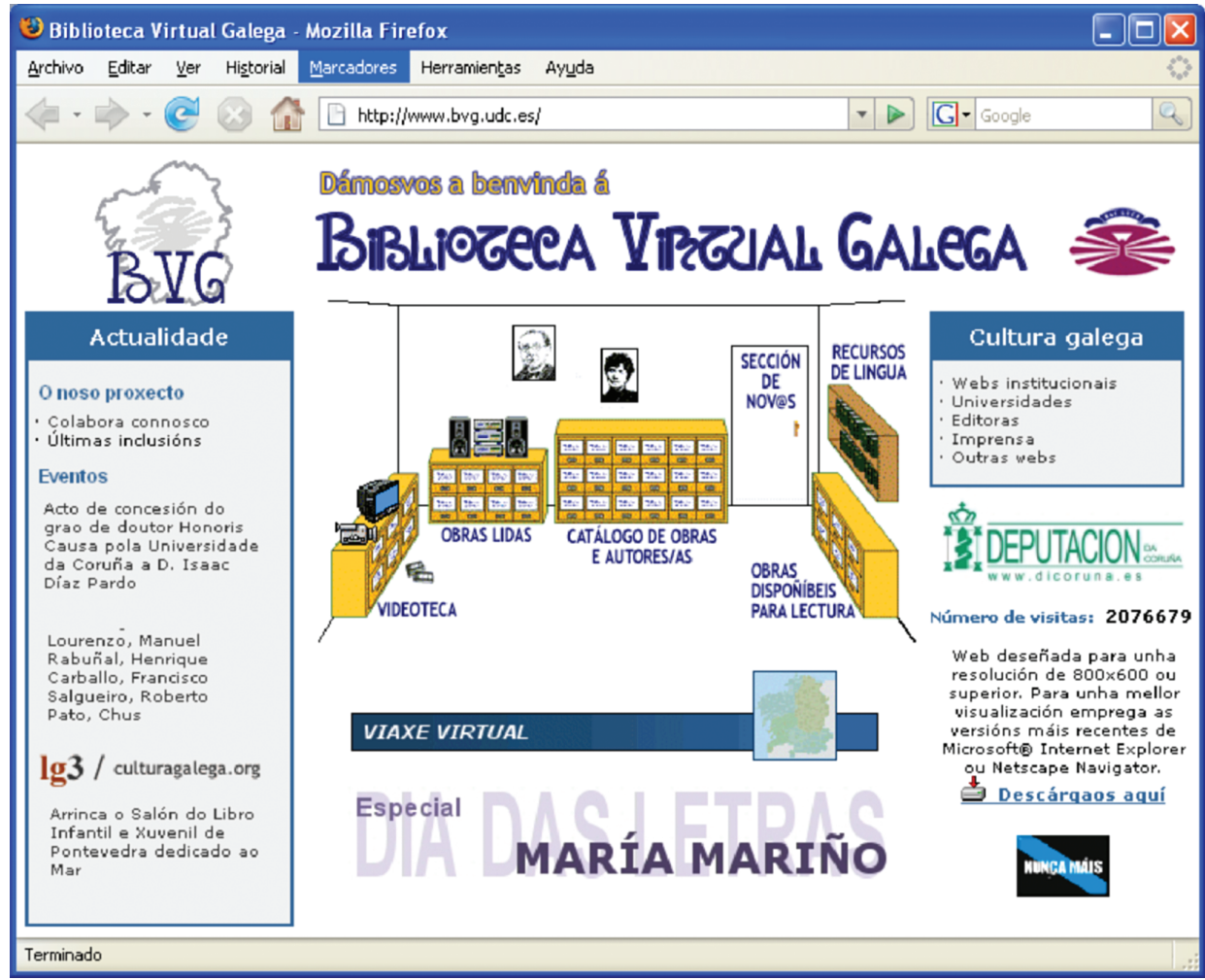

Para proporcionar un medio que ofrezca una comunicación directa entre los autores "normales" y su público, cada autor tiene su propia página Web en la Biblioteca Virtual, donde está disponible su biografía (autobiografía, si el autor está vivo), junto con sus obras. Además, todos los autores tienen una sección de "Novedades", donde pueden informar al público de futuros eventos. También es posible para cualquier usuario enviar un mensaje o comentario al autor, promoviendo de este modo una comunicación directa entre escritores y lectores.

- Una sección de "Novedades", que incluye una "descripción de nuestro proyecto”. Esta sección ofrece novedades en general (eventos de interés próximos) o novedades en las páginas Web de los autores incluidos en la biblioteca.

- Un conjunto organizado de enlaces a páginas Web de interés acerca de Galicia. Ésta es una lista categorizada que incluye páginas Web institucionales, universidades, editoriales y Webs de Galicia en general. 
- El Viaje Virtual a través de Galicia, al cual se accede haciendo clic en el mapa situado en la parte inferior central de la página. Su descripción es el objetivo principal de este trabajo, así que será descrito en las próximas secciones.

\section{TECNOLOGÍA Y DATOS UTILIZADOS PARA CREAR EL VIAJE VIRTUAL}

En esta sección describimos el modelo de datos de la información gestionada por el Viaje Virtual, para ofrecer una idea del tipo y la cantidad de información gestionada. También comentamos brevemente la tecnología utilizada para construir dicho Viaje Virtual.

\subsection{MODELO DE DATOS}

Antes de detallar la información almacenada en nuestra base de datos, cuyo modelo Entidad-Relación (diagrama que muestra los objetos y relaciones de los que se guarda información en el sistema) se muestra en la Figura 4 y, debido a que podemos encontrar elementos de distinta naturaleza en ella, necesitamos clasificarla en las siguientes categorías:

- Datos alfanuméricos, como el nombre y la dirección de un museo, un número de teléfono o el nombre de una carretera.

- Información geográfica: Aquellas entidades que deben ser referenciadas geográficamente deben tener asociado un atributo geométrico. Este atributo puede ser de cualquiera de los tres tipos geométricos definidos: un punto, una línea o un área.

- Información multimedia: La información multimedia utilizada en nuestro sistema consiste principalmente en fotografías, aunque también incluye videos y sonidos.

Figura 4. Modelo Entidad-Relación para el Viaje Virtual

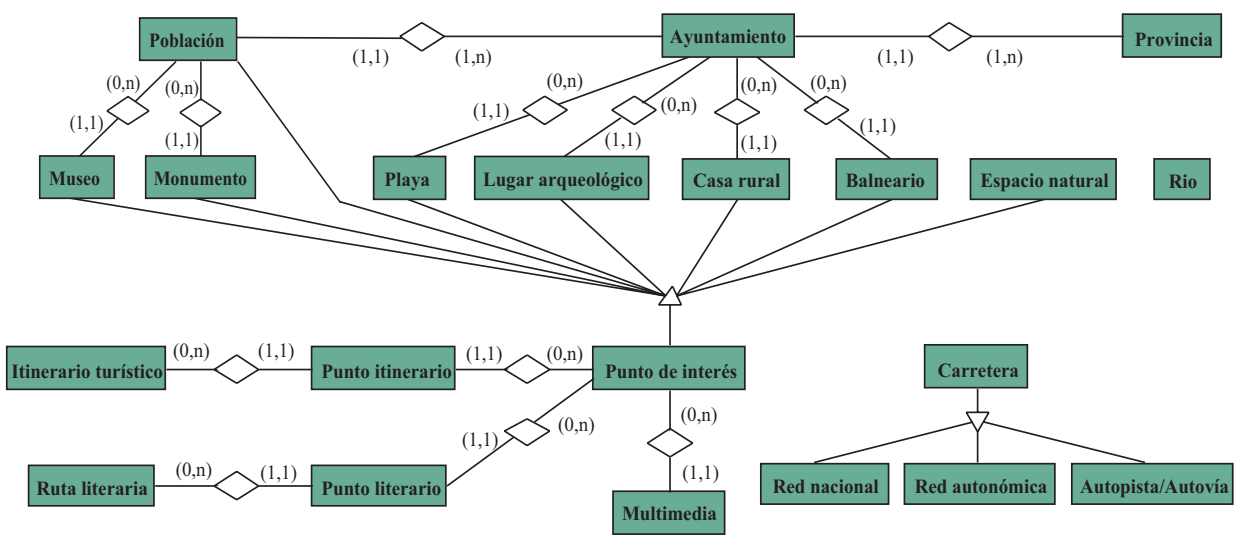


Los distintos objetos de los que se almacena información en nuestro sistema pueden clasificarse en las siguientes categorías:

- Estructura territorial: Como en el resto de España, la comunidad autónoma de Galicia está dividida en provincias, y cada una de ellas dividida a su vez en ayuntamientos. Finalmente, cada ayuntamiento puede tener una o más poblaciones. Las dos primeras entidades, provincia y ayuntamiento, se representan con un atributo geográfico de área, y las poblaciones se representan con un punto. La importancia de esta información es, como veremos más adelante, que constituye la mejor referencia para el usuario al navegar a través del mapa.

- Red de carreteras: Hay información para las vías de circulación más importantes de Galicia (carreteras autonómicas, nacionales, autopistas y autovías), y se representan utilizando atributos geográficos de tipo línea, sin ninguna información multimedia asociada.

- Entidades culturales: Esta categoría incluye lugares arqueológicos, museos y monumentos, como iglesias o castillos. Normalmente, estos lugares tienen asociada información multimedia. Los lugares arqueológicos están representados por puntos mientras que los museos y monumentos no tienen una información geográfica específica. Sin embargo, dado que son edificios y están localizados en una población (referenciada geográficamente como un punto), es posible saber su localización aproximada.

- Recursos turísticos: Esta categoría incluye balnearios y casas rurales, así como servicios de alojamiento en parajes naturales de interés. Los elementos de esta categoría se representan por un punto y también pueden contener información multimedia.

- Naturaleza: Utilizada para representar principalmente playas, espacios naturales y ríos, en esta categoría se almacena también información multimedia asociada a dichos lugares. Se representan geográficamente por objetos del tipo punto, área y línea respectivamente.

- Rutas literarias e itinerarios turísticos: Son rutas que incluyen varios puntos de interés turístico relacionados. Un atributo geográfico línea los enlaza y muestra las líneas de comunicación que pueden ser utilizadas para recorrer la ruta en cuestión.

\subsection{TECNOLOGÍAS UTILIZADAS Y ARQUITECTURA DEL SISTEMA}

La Web "Viaje virtual a través de Galicia" integra distintos formatos y tecnologías, algunas de ellas bastante recientes en Internet, para ofrecer al usuario la posibilidad de buscar de forma rápida y sencilla información sobre Galicia.

La Figura 5 muestra los distintos componentes que integran el sistema. La tarea de publicar información geográfica en la Web implica el diseño e implementación de una aplicación cliente-servidor, en la que el servidor almacena tanto la información geográfica, como la más "tradicional” información multimedia. El servidor crea los mapas soli- 
citados por el usuario y los transfiere embebidos en una página HTML al cliente, que puede ser cualquier navegador Web. El navegador interpreta esa información y muestra el mapa al usuario.

La información se guarda en un sistema de gestión de bases de datos PostgreSQL, extendido con un módulo PostGIS utilizado para gestionar la información geográfica. Dicha información es extraída de la base de datos por un Servicio Web de Mapas (WMS) que recibe peticiones y devuelve como resultado mapas en el formato vectorial de imagen SVG (Scalable Vectror Graphics). Este mapa es procesado por un módulo que emplea la tecnología JSP (Java Server Pages) para crear la página Web, con el mapa embebido, que se envía al navegador del usuario. Finalmente, un applet (un componente de una aplicación que se ejecuta dentro de otro programa, como puede ser un navegador Web) da soporte a la interacción del usuario con el mapa en su navegador Web.

Figura 5. Arquitectura del sistema

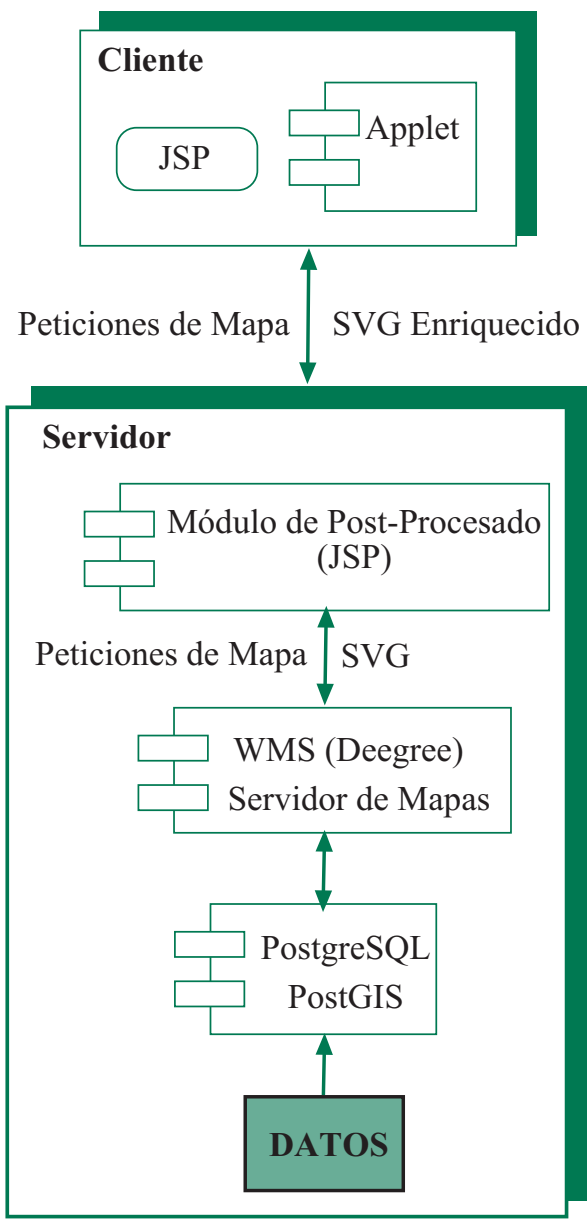




\section{LA INTERFAZ DEL "VIAJE VIRTUAL POR GALICIA"}

El diseño de la página Web que ofrece el Viaje Virtual por Galicia se ha llevado a cabo teniendo en cuenta las ideas descritas en secciones anteriores y utilizando metáforas cognitivas. En esta sección describimos cómo funciona la interfaz, explicando cuándo y cómo fue aplicada esta técnica.

El sistema fue diseñado no sólo para buscar información sobre Galicia, sino también para planificar itinerarios que puedan ayudar a mejorar el conocimiento sobre la cultura gallega. Para alcanzar este objetivo, utilizamos un mapa interactivo de Galicia como principal metáfora cognitiva.

Como ya discutimos anteriormente, la principal ventaja de utilizar un mapa es que prácticamente todo el mundo es capaz de usar e interpretar un mapa. Todos los elementos geográficos son rápidamente identificados (para aquellos elementos no muy comunes en mapas, como balnearios o casas rurales, se incluye una leyenda explicando su significado).

Un mapa real ayuda a localizar un lugar, pero normalmente no ofrece ninguna forma de obtener información adicional sobre él. En nuestro mapa, cuando un usuario mueve el ratón sobre un área del mapa, ésta es destacada y se muestra su nombre. Si el usuario hace clic en dicha área, una ventana muestra información adicional del lugar. Por ejemplo, al mover el ratón sobre el mapa se destacan todos los ayuntamientos y se muestran sus nombres. Haciendo clic en cualquiera de ellos, el usuario puede abrir una nueva ventana que le informa sobre el número de monumentos, playas, lugares arqueológicos, etc., localizados en ese ayuntamiento.

\subsection{EL DISEÑO DE LA PÁGINA WEB DEL VIAJE VIRTUAL}

La página Web para el Viaje Virtual, mostrada en la Figura 6, ofrece dos áreas principales: el área del mapa, y el área del menú. El área del mapa muestra un mapa, de toda Galicia, o de una de sus provincias, permitiendo al usuario obtener información de cualquiera de los elementos mostrados. El área del menú, al igual que la fila de accesos en la parte superior derecha de la página permite seleccionar la información de interés (que será mostrada en el mapa) o buscar un lugar determinado.

El mapa, que se muestra en la parte derecha de la interfaz, muestra inicialmente las cuatro provincias de Galicia y los ayuntamientos de cada una de ellas, aunque también pueden mostrarse otros elementos. Como es de esperar, todos los mapas son sensibles a las acciones del usuario. La Figura 2 muestra un ejemplo: cuando se hace clic en un monumento, en este caso el Castillo de San Antón, se muestra una fotografía del monumento junto con la información disponible sobre él.

\subsection{INTERACCIÓN BÁSICA}

Además de obtener información sobre los elementos mostrados en el mapa al mover el ratón sobre ellos, destacándolos y abriendo ventanas con información adicional, el usuario puede modificar el mapa que le muestra el sistema de dos formas: 
Figura 6. Vista general del sistema

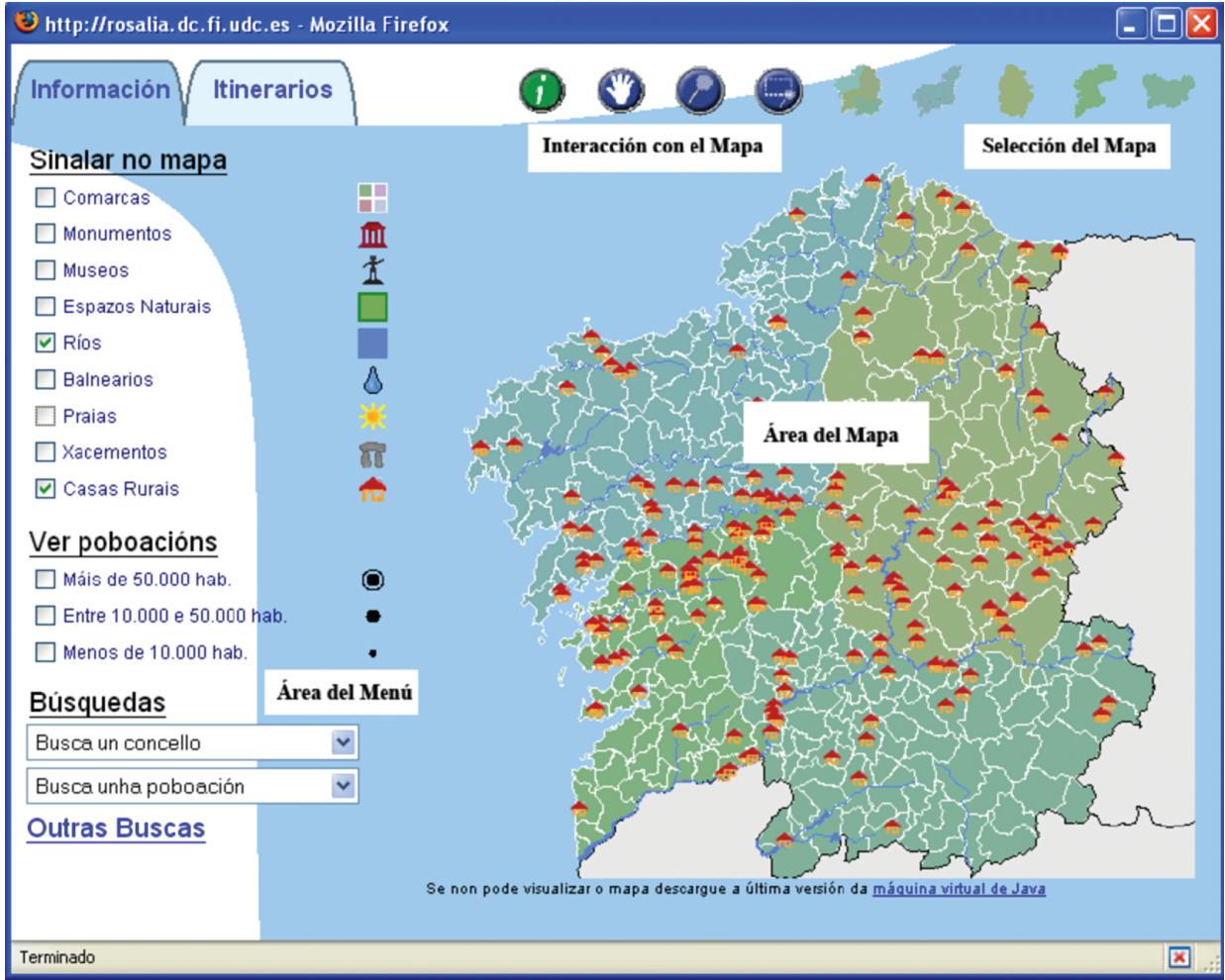

- Elegir un mapa diferente o modificar el actual: El mapa inicial muestra la comunidad autónoma de Galicia, con sus cuatro provincias y todos los ayuntamientos. Los accesos mostrados encima del mapa en la página Web permiten seleccionar una de las provincias (A Coruña, Lugo, Pontevedra y Ourense) para mostrar un mapa de la provincia seleccionada y todos sus ayuntamientos. Las opciones de visualización y búsqueda quedan restringidas a esa provincia.

Además, en la parte superior del mapa podemos encontrar una fila de botones que permiten modificar el mapa que estamos viendo en un momento dado. Utilizando dichos botones podemos aumentar el zoom sobre el mapa, moverlo o ampliar una zona determinada.

- Modificar el tipo de información mostrada en el mapa actual: En secciones anteriores hemos explicado que hay distintas categorías de información asociadas a cada lugar geográfico, como redes de carreteras, playas o monumentos. El área de menú de la parte izquierda de la página permite seleccionar cuáles de estas categorías de información se muestran en el mapa actual. Esto puede hacerse gracias a la estructura en capas de los mapas, donde cada capa agrupa a las entidades geográficas de una categoría dada (playas, museos, rutas, etc.), que pueden ser mostradas o no. Así, al seleccionar varias casillas se superponen sus correspondientes capas, formando un mapa más o menos complejo a elección del usua- 
rio. La Figura 6 muestra un ejemplo en el que se crea un mapa que muestra los ayuntamientos y provincias (esta información siempre se muestra) junto con los ríos y casas rurales.

La estructura en capas del mapa tiene dos ventajas principales: la primera de ellas es que evita llevar a cabo consultas innecesarias para acceder a la información de uno o varios elementos que no se van a mostrar, mejorando así el tiempo de respuesta del sistema; además, ayuda a mejorar la navegación por el mapa, ya que aquella información que carece de interés para el usuario no se muestra, lo que le permite localizar más fácilmente la información en la que sí está interesado. Por ejemplo, si un usuario quiere localizar los lugares de interés arqueológico cerca de la costa, puede activar la visualización de esa capa e identificar visualmente cuáles están cerca de la costa.

Como se puede ver en la Figura 6, el área de menú tiene dos pestañas: "Información" e "Itinerarios". Ambas están compuestas de un conjunto de casillas de verificación que permiten mostrar u ocultar en el mapa las capas que tienen asociadas, dependiendo de si la casilla está marcada o no.

La pestaña de "Información" puede utilizarse para activar o desactivar capas compuestas de elementos individuales, como museos, playas, balnearios, casas rurales o espacios naturales. La segunda pestaña, "Itinerarios", se utiliza para mostrar distintos itinerarios turísticos y rutas literarias en el mapa. Los elementos de interés cercanos a la ruta, así como su trayectoria, se muestran en el mapa. Este menú también permite visualizar distintas redes de carreteras de Galicia o de alguna de sus provincias. La Figura 7 muestra un mapa con dos itinerarios y la red de autopistas/autovías de Galicia.

Como hemos discutido anteriormente, los itinerarios pueden tener distintos usos dependiendo del nivel de conocimiento del turista sobre Galicia y su cultura, desde rutas en áreas determinadas hasta itinerarios literarios o de peregrinaje.

- Realizar búsquedas: Los usuarios también pueden realizar búsquedas, utilizando para ello el área de búsqueda que podemos encontrar en la parte inferior del área de menú. Las consultas más comunes, búsqueda de ayuntamientos y poblaciones, son las más sencillas: se selecciona en una lista el nombre del ayuntamiento o población en cuestión, y éste se muestra en el mapa. Esta operación puede realizarse gracias a que la información alfanumérica del elemento y su información geográfica están enlazadas en la base de datos.

Las búsquedas sobre puntos de interés turístico o cultural se llevan a cabo utilizando una interfaz muy sencilla en la que el usuario marca la casilla correspondiente al elemento que está buscando y escribe su nombre o una parte de él (se aplica una aproximación utilizando técnicas de recuperación de textos, por lo que no es necesario escribir el nombre completo). El resultado es una lista con los nombres de los elementos que satisfacen el criterio de selección. Es posible obtener la información disponible para cada uno de los resultados o mostrarlos parpadeando en el mapa para que sean más fáciles de encontrar. 
Figura 7. Itinerarios y redes de carreteras

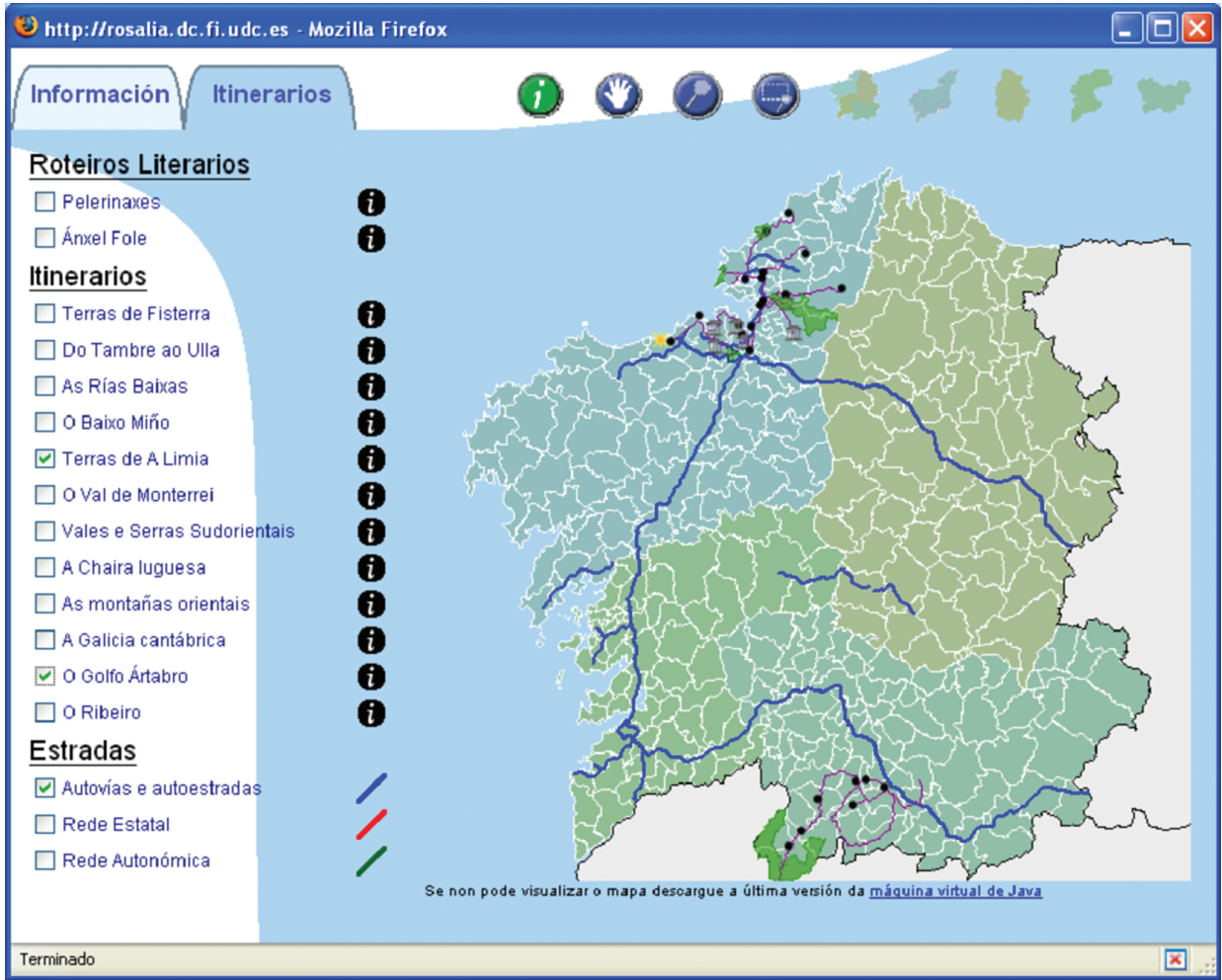

\subsection{PLANIFICANDO UN VIAJE}

Uno de los objetivos que nos llevó a desarrollar el Viaje Virtual a través de Galicia era ofrecer una herramienta que pudiera ser utilizada para planificar un viaje a través del territorio gallego. Aunque no se descarta el turismo masivo, el Viaje Virtual no está orientado a este tipo de turismo. La audiencia principal que se tenía en mente era gente buscando turismo cultural. Este tipo de turistas suele estar interesado en planificar sus viajes de forma que les permita mezclarse con la gente y las costumbres tradicionales, al mismo tiempo que disfrutar lugares agradables y absorber la cultura e historia de los lugares que visitan. Si este turismo se realiza visitando pueblos y lugares pequeños y dispersos, la necesidad de planificarlo es evidente. Esto es especialmente importante en Galicia, ya que debido a su topografía y cultura rural, la mayoría de los lugares de interés están dispersos por todo el territorio gallego. Sin embargo, también consideramos las grandes ciudades ya que, como todos sabemos, muchos museos, monumentos y lugares de descanso están situados cerca de ellas.

Teniendo en mente estos hechos, un turista potencial puede utilizar nuestro mapa para planificar un viaje por Galicia. El uso del área de mapa del Viaje Virtual es de ayuda para esta tarea, ya que se pueden ver las categorías individuales de información de forma 
que sea fácil encontrar el camino más corto que cubra todos los lugares en que el turista esté interesado. También es de gran ayuda en la planificación del viaje poder visualizar las redes de carreteras disponibles.

Por otra parte, los usuarios también pueden aprovechar los recorridos predefinidos. Utilizando la pestaña de "Itinerarios" en el área de menú, pueden elegir la opción de seguir rutas que siguieron en su día personas significativas para la cultura gallega, como escritores por ejemplo, o rutas de peregrinaje. Por este motivo, el sistema pone a disposición del usuario varias rutas que se destacan en el mapa si así lo desea, mostrando los puntos de interés turístico en torno a la ruta. Por supuesto, debido a que toda la información se puede mostrar en los mapas, los usuarios pueden elegir la opción de seguir una ruta predefinida hasta cierto punto, y desviarse después para visitar otros lugares que le interesen más. De esta forma, los usuarios pueden personalizar fácilmente las rutas de viaje.

\section{CONCLUSIONES}

Internet ha cobrado una relevancia muy importante en los últimos años y, cada día, se crean muchas páginas Web. El turismo no ha sido ajeno a esta nueva tecnología; sin embargo, las características especiales de la información turística, especialmente su naturaleza espacial, hacen que el diseño de interfaces Web turísticas amigables y fáciles de usar sea una tarea difícil.

El diseño de la mayoría de las páginas Web con información turística hasta la fecha está basado en una oferta de información estática, con una mezcla de textos y mapas no interactivos. En este trabajo hemos utilizado una combinación de tecnologías SIG y bases de datos multimedia para mejorar las interfaces Web y ofrecer la posibilidad de interaccionar con los mapas. Aunque las tecnologías SIG son ampliamente utilizadas en áreas como servicios públicos o ingeniería civil, creemos que también pueden ser una herramienta de valor en el caso de la información turística.

Además, hemos utilizado técnicas bien conocidas en el área de investigación conocida como Interacción Hombre-Máquina para crear interfaces intuitivas y fáciles de utilizar. Teniendo en cuenta el nivel de aceptación y la retroalimentación de los usuarios que han consultado nuestro Viaje Virtual por Galicia, creemos que los usuarios pueden, en general, verse beneficiados por este enfoque, por lo que la filosofía que hemos seguido en la creación de este sistema puede aplicarse al desarrollo de cualquier portal de información turística.

Como trabajo futuro tenemos varias tareas que completar. Una de estas tareas es la traducción del portal Web a varios idiomas, como el español y el inglés, para que también puedan utilizarlo los usuarios que no hablen gallego. También sería deseable que el sistema pudiera ofrecer un foro para usuarios interesados, algo que podría mejorar el sentido de comunidad entre ellos. Finalmente, dejamos como trabajo futuro la integración del Viaje Virtual con servicios de gran interés para los usuarios que planifican su viaje, como la reserva de hoteles, compra de billetes, etc., integrando nuestro sistema con distintas soluciones de comercio electrónico. 


\section{BIBLIOGRAFÍA}

Brisaboa, N. R., Cotelo, J. A. , Fariña, A., Luaces, M. R., Paramá, J. R., Viqueira, J. R. (2007): "Collecting and publishing massive geographic data", Software-Practice and Experience. 37(12): 1319-1348.

Brisaboa, N. R., Fariña, A., Luaces, M. R., Paramá, J. R., Penabad, M. R., Places, A. S., Viqueira, J. R. (2003): "Using Geographical Information Systems to Browse Touristic Information”, IT\&T: Information, Tourism and Technology, 6(1): 31-46. USA.

Brisaboa, N. R., González, P.A., Lorenzo, M., Luaces, M. R. (2006): “Proceso de transformación de webEIEL en un nodo de la red de IDEs (ideAC). Estado actual y actuaciones de futuro", en Carlos Granell y Michael Gould (ed.) Avances en Las Infraestructuras de Datos Espaciales, pp. 31-49, Publicaciones de la Universitat Jaume I. Castellón de la Plana (España).

Longley, Goodchild, Maguire, Rhind. (2001): Geographic Information Systems And Science, Wiley.

González, P.A., Lorenzo, M., Luaces, M. R., Paramá, J. R. (2007): “Un nodo local de la IDE de España: ideAC", La Infraestructura de Datos Espaciales de España en 2007. Proyectos, servicios y nodos, pp. 186-197. Santiago de Compostela (España).

ISO. (2002): ISO/IEC 13249-3:2002, Information Technology_ Database Languages SQL Multimedia and Application Packages-Part 3: Spatial, International Organization for Standardization (ISO). Working draft.

Preece, J. (1994): Human-computer interaction, Reading, MA: Addison Wesley.

Schneiderman, B. (1997): Designing the user interfaz. Reading, MA: Addison Wesley.

Taboada González, J.A. y Cotos Yáñez, J.M., eds. (2005): Sistemas de Información Medioambiental, A Coruña, Netbiblo.

Worboys, M. F. (2000): GIS. A computing perspective. Taylor \& Francis.

Zetie, C. (1995): Practical user interfaz design: Making GUIs work. New York: McGraw Hill. 